Proceedings

\title{
Innovation in Teacher Education: An Integrative Approach to Teaching and Learning Science and Mathematics ${ }^{+}$
}

\author{
Nelson Mestrinho * and Bento Cavadas \\ Department of Mathematical and Natural Sciences, School of Education-Polytechnic Institute of Santarem, \\ 2000-902 Santarem, Portugal; bento.cavadas@ese.ipsantarem.pt \\ * Correspondence: nelson.mestrinho@ese.ipsantarem.pt; Tel.: +351-963097774 \\ + Presented at the 2nd Innovative and Creative Education and Teaching International Conference \\ (ICETIC2018), Badajoz, Spain, 20-22 June 2018.
}

Published: 29 October 2018

\begin{abstract}
CreativeLab_Sci\&Math is a project set by the Department of Mathematical and Natural Sciences of Polytechnic Institute of Santarém / School of Education, with the purpose of promoting innovative teaching of science and mathematics, involving students in interdisciplinary activities that connect content and processes of knowledge from both areas, using inquiry-based learning and the $6 \mathrm{E}$ teaching model.
\end{abstract}

Keywords: 6E teaching model; earth and life sciences; inquiry-based learning; integrated mathematics and science education; innovative learning environments; interdisciplinarity; mathematical modelling; teacher education

\section{Introduction}

Integration of mathematics and science teaching promotes student's conceptual understanding of these two areas, and a better comprehension of the many connections and applications that link science and mathematics [1]. Several studies show this integration facilitate students' engagement, critical thinking and problem-solving skills [2]. However, school curricula tend to segregate knowledge into isolated subjects. To develop a curriculum that effectively integrates science and mathematics in school, it is important to provide rich and meaningful experiences to prospective teachers, to engage them in interdisciplinary teaching practices and understanding of such connections [1]. Though, in higher education and particularly in Portuguese elementary school teacher education programs, subdivision of areas is a huge obstacle to curriculum integrative approaches.

The main purpose of this paper is to present an integrated approach to mathematics and science teaching in higher education, involving the courses of Earth and Life Sciences and Mathematical Modelling of Basic Education Degree. This Degree is the first stage of formation of kindergarten/elementary school teachers in Portugal. Earth and Life Sciences and Mathematical Modelling are focused in subject matter knowledge and not on didactics. We consider our approach an innovative practice in higher education because it introduces a culture of collaboration between mathematics and science teachers before, during and after classroom. In the following sections, we are going to present the principles, methods and outcomes of our approach, related to the engagement of students in activities that connect contents and processes of knowledge from both areas, as a part of a common core curricular design for both courses, and developed in an innovative learning environment, the CreativeLab_Sci\&Math. 


\section{Integrating Science \& Mathematics Teaching}

In Portugal, obtaining qualification for teaching requires a degree in a higher education institution (depending on the subject area and school level), followed by a professional master degree. For prospective kindergarten or elementary school teachers this means obtaining a degree in Basic Education (common to both profiles) and a master which specifies their professional profile. Earth and Life Sciences and Mathematical Modelling are two mandatory courses for the 3rd year undergraduates of Polytechnic Institute of Santarem/School of Education, delivered in the 2nd semester. So, the whole class must attend both courses in the same semester. This fact became the opportunity we needed to design syllabi for both courses that, without compromising their specific learning outcomes, includes a common core of interdisciplinary activities. Figure 1 illustrates the conceptual network that we create to organize our work. At the center of the figure there are the interdisciplinary activities that link contents of both courses, developed and implemented according to the didactical approach presented in the next section.

EARTH AND LIFE SCIENCES

MATHEMATICAL MODELLING

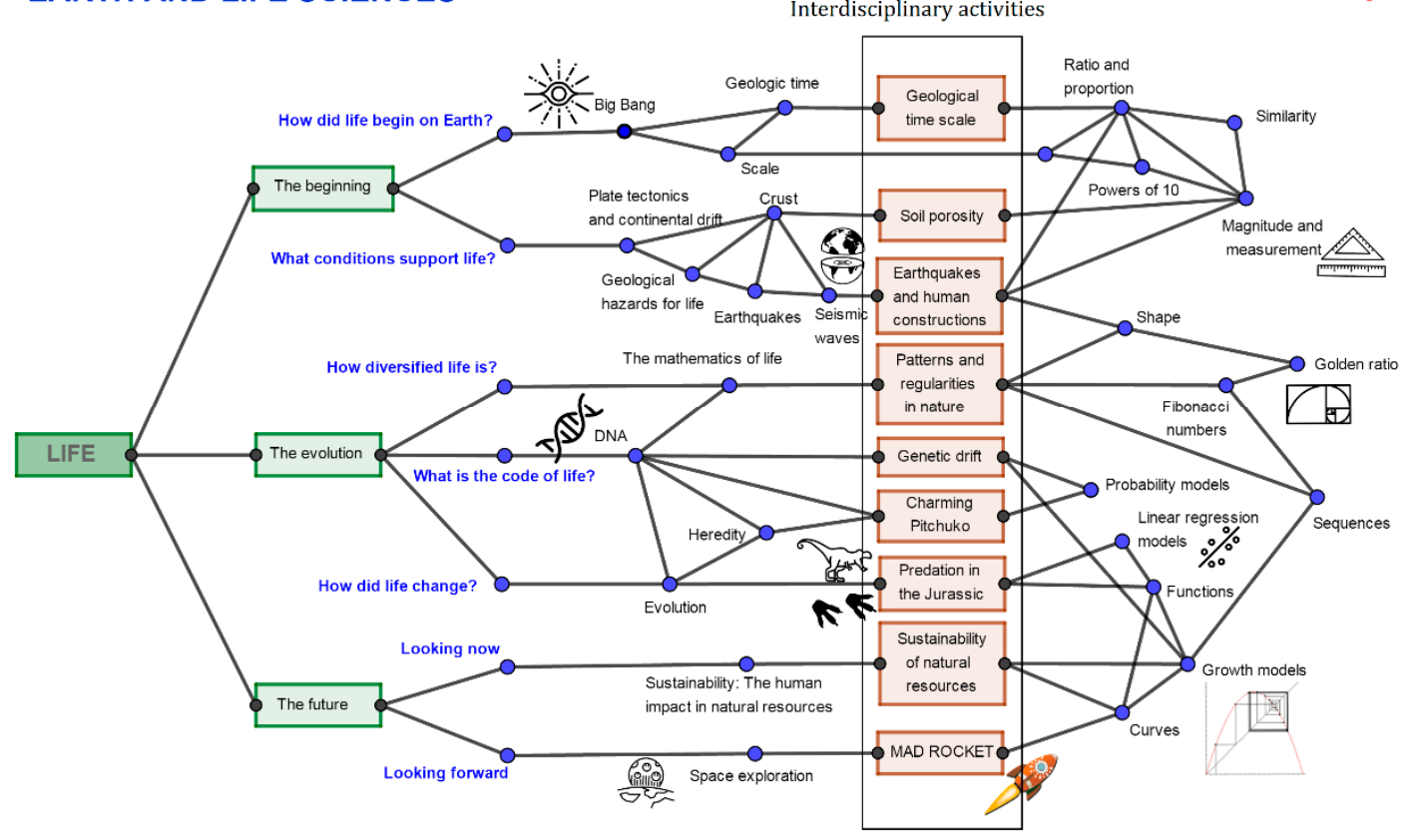

Figure 1. Conceptual network linking topics within and between the two courses. At the center there are the interdisciplinary activities that promote the integrative approach of both subjects.

The core idea of this integration was life. In Earth and Life Sciences, students start with the study of life's origin, followed by the learning of life's evolution and the future of life and mankind. The subjects concerning Earth and Life Sciences provided contexts for the emergence of several mathematical themes. Concepts and methods of Mathematical Modelling, namely the modeling cycle, allowed to solve problems or describe real-life or contextualized situations [3]. These interdisciplinary activities permitted us to involve students in inquiry and meaningful learning experiences, interconnecting the scientific content of both courses.

\section{The Didactic Approach}

Integrating mathematics and science teaching can result from the close connection between these areas. Science provides concrete contexts for the application of mathematical concepts, and mathematics allows students to deepen their understanding of scientific ideas, trough providing tools to quantify and explain science relationships, expressed in variables, equations, graphs, charts, etc. [2,4].

CreativeLab_Sci\&Math is a project set by the Department of Mathematical and Natural Sciences of the Polytechnic Institute of Santarem/School of Education with the purpose of promoting teaching 
innovation of science and mathematics. One of the aims of that project is the construction, implementation and assessment of interdisciplinary activities that connect scientific contents and processes of knowledge construction from both areas. Working mainly within teacher education program contexts, we highlight the strong collaborative work of teachers of both subjects, the use of inquiry-based learning approaches, and the shift from a traditional classroom to an innovative learning environment. This implies rethinking the spatial organization of the classroom, its resources, teaching strategies, and teachers' and students' roles [5]. CreativeLab_Sci\&Math space is the result of the transformation of a classic laboratory into an innovative educational environment, shaped for laboratory work, use of educational media and other science and mathematics educational resources (Figure 2). It is organized into different learning areas related to 6E teaching moments and students' different needs concerning the realization of the tasks, that promote development of different skills.

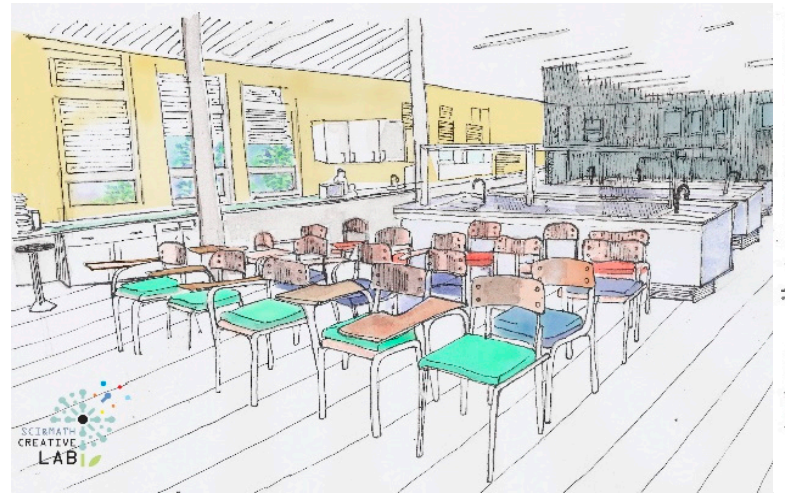

(a)

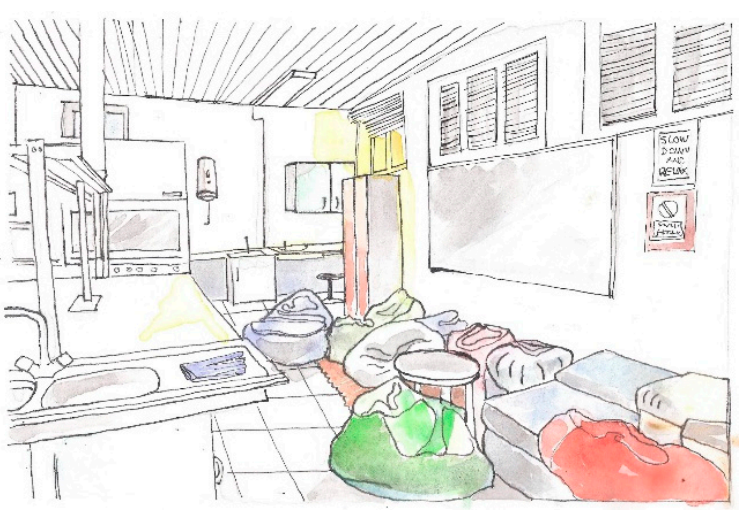

(b)

Figure 2. CreativeLab_Sci\&Math space (art by Clara Brito). Area with the chairs (a) is related to the Engage, Explain and Exchange moments. Behind it, students can work in three areas in large groups and do laboratorial activities or explore digital resources (Explore, Exchange, Evaluate). In the left side, there is an area where students can also work alone or in small groups. At the end of the classroom (b), there is a working space with lounge characteristics that can be used by students in Engage, Exchange or Explore moments.

To effectively link and overlap topics from both areas, mathematics and science teachers work together in designing student's guides for exploration of interdisciplinary activities. These activities are implemented with students in the presence of the science and mathematics teachers at same time in CreativeLab_Sci\&Math. This approach allows a convergence in the activities objectives without compromising some specific learning outcomes of each subject. This collaboration is beneficial to development of pedagogical and content knowledge for both teachers involved [1,6].

CreativeLab_Sci\&Math learning activities are structured using inquiry-based learning. They are student-centered and promote critical thinking, reflection and self-assessment, group work, autonomy and scientific literacy [7]. Interdisciplinary activity guides are organized according to $6 \mathrm{E}$ teaching model, which includes the following moments: Engage, Explore, Explain, Exchange, Elaborate and Evaluate [8,9].

The main goal in Engage moment is students' involvement in a subject or problem. In this moment, it is important to understand students' prior knowledge regarding the subject or problem in study and promote connections between previous and new learning experiences. Social media are also used to promote students' engagement in activities. In Explore moment, students are involved in hands-on and minds-on science and mathematics activities that help them generate new ideas, explore questions and hypothesis, design a methodology and conduct a research for address the problem posed. In this moment, laboratorial, digital and other resources are provided to help students in their inquiry. Explain moment is used to focus the students' attention in scientific details of a concept or process, providing opportunities to demonstrate their comprehension of the subject. When necessary, teachers give direct explanations or lead them to further inquiry, promoting an accurately scientific common language. Elaborate moment is used to engage students in new learning 
experiences by developing a more profound comprehension of science and mathematics topics addressed in previous moments, transferring them to new situations. Exchange moment includes the presentation, by groups or individual students, of what they have learned. At this moment they need to be ready to answer questions placed by peers and/or by the teachers. During activities, there are several moments that promote group discussions and cooperative learning, giving opportunities for students to present their ideas and receive feedback from peers. In some exchange moments, students must also work together to collect and share data that it will be used to achieve collective answers to a problem. Evaluate moment provides opportunities for students to assess their comprehension of science and mathematics subjects addressed, evaluate their skills development and receive feedback from teachers. Some interdisciplinary activities include an extra ' $E$ ' moment, Empowerment, to raise students' awareness about socio-scientific issues and promote transfer of knowledge to community to help solving a problem.

\section{Conclusions}

In this work we have presented a science and mathematics interdisciplinary teaching experience in higher education, centered in learning through inquiry, the $6 \mathrm{E}$ teaching model and use of an innovative learning environment, the CreativeLab_Sci\&Math. Through our evaluation of the guides filled by students, their performance during activities and the students' didactic evaluation of our interdisciplinary approach, we have confirmed that integration of science and mathematics teaching enables the development of students' engagement, critical and creative thinking, reasoning and problem-solving skills, while it promotes a deeper conceptual understanding of both subjects [2]. It was clear that science provided contexts for the emergence of several mathematical themes, and mathematics aided to underscore the importance of careful observation, data collection, logical thinking and modelling as part of the scientific method, as stated in [10]. On the other hand, since teacher educators' practices are important references for students as prospective teachers [11], we believe that learners' involvement in such kind of activities can promote a less compartmentalized view of science and mathematics education, being an example of how interdisciplinary practices can be placed into action.

Author Contributions: The authors N.M. and B.C. have conceived and implemented collaboratively the teaching experiment reported in this paper. The conception of this paper was done likewise, in cooperation, being both contributions equivalent. N.M. wrote the text final version.

Conflicts of Interest: The authors declare no conflict of interest.

\section{References}

1. Frykholm, J.; Glasson, G. Connecting science and mathematics instruction: Pedagogical context knowledge for teachers. Sch. Sci. Math. 2005, 105, 127-141.

2. Ní Ríordáin, M.; Johnston, J.; Walshe, G. Making mathematics and science integration happen: Key aspects of practice. Int. J. Math. Ed. Sci. Technol. 2015, 47, 1-23, doi:10.1080/0020739X.2015.1078001.

3. Borromeo Ferri, R. Theoretical and empirical differentiations of phases in the modelling process. ZDM 2006, 38, 86-95.

4. Bosse, J.; Lee, D.; Swinson, M.; Faulconer, J. The NCTM process standards and the five “Es" of science: Connecting math and science. Sch. Sci. Math. 2010, 110, 262-276.

5. OECD. Innovative Learning Environments, Educational Research and Innovation. OECD Publishing. 2013. Available online: http://dx.doi.org/10.1787/9789264203488-en (accessed on 24 March 2018).

6. Morrison, J.; McDuffie, A.R. Connecting science and mathematics: Using inquiry investigations to learn about data collection, analysis, and display. Sch. Sci. Math. 2009, 109, 31-44.

7. Hutchings, W. Enquiry-Based Learning: Definitions and Rationale; The University of Manchester: Manchester, UK, 2007.

8. Bybee, R.W.; Taylor, J.A.; Gardner, A.; Scotter, P.V.; Powell, J.C.; Westbrook, A.; Landes, N. The BSCS 5E Instructional Model: Origins and Effectiveness; BSCS: Colorado Springs, CO, USA, 2006. 
9. Kähkönen, A.-L. Models of Inquiry and the Irresistible 6E Model. 2016. Available online: http://www.irresistible-project.eu/index.php/pt/blog-pt/168-models-of-inquiry-and-the-irresistible-6emodel (accessed on 24 March 2018).

10. Hollenbeck, J.E. Integration of Mathematics and Science: Doing it correctly for once. BJSEP 2007, 1, 77-81.

11. Formosinho, J. Formação de Professores-Aprendizagem Profissional e Acção Docente; Porto Editora: Porto, Portugal, 2009.

(C)

(C) 2018 by the authors. Licensee MDPI, Basel, Switzerland. This article is an open access article distributed under the terms and conditions of the Creative Commons Attribution (CC BY) license (http://creativecommons.org/licenses/by/4.0/). 